\title{
Plurilinguismo para o ensino fundamental brasileiro
}

\section{Plurilingualism for Brazilian elementary education}

\author{
Priscilla Barbosa de Oliveira Melo* \\ pbomelo@yahoo.com \\ Universidade Estadual de Feira de Santana
}

\begin{abstract}
RESUMO: Refletir sobre o uso da linguagem e sobre a aula de língua estrangeira e seu relevante papel sociocultural nos faz pensar em possibilidades de ampliar o repertório linguístico e cultural do aluno. Consequentemente, chegamos ao estudo do plurilinguismo, a saber, a experiência pessoal e cultural, do indivíduo em diferentes línguas. Para tanto, pretende-se explorar os documentos oficiais que estão em uso no Brasil e trazer também documentos internacionais que estão - de certa forma e até certo grau - presentes nos estudos e na produção acadêmica do Brasil, e assim constatar a presença do plurilinguismo pedagógica e legislativamente no país. Para a elaboração deste artigo, far-se-á uma pesquisa de levantamento bibliográfico dos documentos oficiais para o ensino de línguas sobre o plurilinguismo voltado para a educação básica - mais especificamente o $3^{\circ}$ e o $4^{\circ}$ ciclo do ensino fundamental II no que se diz respeito ao ensino de línguas. Este artigo buscou, no cenário educacional, o lugar do plurilinguismo e, deste modo, evidenciou sua consolidada presença e importância na atualidade para a formação do aluno, do professor, como também para sua prática em sala de aula.
\end{abstract}

PALAVRAS-CHAVE: Plurilinguismo. Ensino fundamental. Documentos oficiais.

\begin{abstract}
Reflecting on the use of language and on the foreign language class and its relevant socio-cultural role makes us think of possibilities to expand the student's linguistic and cultural repertoire. Consequently, we come to the study of plurilingualism, namely, the personal and cultural experience of the individual in different languages. To this end, it is intended to explore the official documents that are in use in Brazil and also to bring international documents that are - to a certain extent and to a certain degree - present in the studies and academic production in Brazil, and thus verify the

\footnotetext{
* Graduada em Letras com Francês pela Universidade Estadual de Feira de Santana (2005), em Pedagogia pela Universidade Santo Amaro (2019) e em Letras Inglês pela Estácio de Sá (2020); Especialista em Língua Portuguesa (2008) e em Metodologia do Ensino do Francês como Língua Estrangeira (2019) e Mestre em Ciências da Educação pela Universidade da Madeira - Portugal (2013). Atualmente, é professora de Língua Portuguesa da rede municipal de ensino em Lauro de Freitas - Ba e professora substituta da Universidade Estadual de Feira de Santana - UEFS, atuando nos cursos Letras e Pedagogia. Tem estudos na área de Letras, com ênfase em Línguas Estrangeiras Modernas, Plurilinguismo, Práticas de Leitura e Produção de Texto e na área de Educação com ênfase em Prática de Ensino e Avaliação Pedagógica.
} 
presence of plurilingualism pedagogical and legislatively in the country. For the elaboration of this article, a search will be made for a bibliographic survey of the official documents for language teaching on plurilingualism aimed at basic education - more specifically the 3rd and 4th cycle of elementary education II - in what is said respect to language teaching. This article sought, in the educational scenario, the place of plurilingualism and, thus, evidenced its consolidated presence and importance today for the formation of the student, the teacher, as well as for their practice in the classroom.

KEYWORDS: Purilinguism. Elementary education. Official documents.

\section{Justificativa}

A globalização trouxe consigo a necessidade de interagir com o mundo e ler suas diferentes linguagens. Neste contexto, as línguas estrangeiras e a língua materna tornam-se facilitadoras para o acesso aos diferentes povos e grupos, às diferentes culturas e ainda aos amplos debates e conhecimentos disponíveis nacional e mundialmente.

Sabe-se que com a tecnologia e o rápido acesso à internet tem-se disponíveis as diversas ferramentas de tradução on line, as quais facilitam este ingresso sociocultural. Todavia, é importante salientar que conhecer idiomas - ao invés de somente traduzi-los utilizando, por exemplo, um software de tradução - promove um profundo mergulho cultural, cuja riqueza é oriunda somente através do idioma nativo de um dado povo. Portanto, acessar a língua de uma nação é conhecê-la mais a fundo, é perceber sua história, seus costumes e suas ideologias e, portanto, interagir com o outro. Além disso, transitar bem em diferentes idiomas, inclusive no próprio idioma, permite que o sujeito, a nosso ver, conquiste autonomia na construção do seu próprio conhecimento, aproximando-o mais e mais do perfil de um consciente cidadão do mundo. Consequentemente, uma perspectiva educacional plurilíngue torna-se central para este cenário no qual estamos inseridos. Então, indaga-se: para se pensar em um ensino fundamental plurilíngue, quais são as orientações presentes nos documentos nacionais da educação básica brasileira?

Refletir sobre o uso da linguagem e sobre a aula de línguas estrangeiras e seu relevante papel sociocultural nos faz pensar em possibilidades de ampliar o repertório linguístico e cultural do aluno brasileiro. Por conseguinte, através de pesquisas neste âmbito, chegamos ao estudo do plurilinguismo - conceito que retomaremos ao longo deste artigo - a saber, a experiência pessoal e cultural do indivíduo em diferentes 
línguas em diversos contextos. Sendo este um campo de estudo não muito comum na prática dos professores brasileiros que atuam em escolas públicas e, portanto, em suas salas de aula de língua estrangeira, vê-se, desta forma, a necessidade de elucidar o assunto e, portanto, estudá-lo a partir da base. Ou seja, buscar compreendê-lo a partir dos documentos que orientam a educação básica brasileira.

Logo, a intenção deste artigo é trazer mais uma contribuição para a área do ensino de línguas estrangeiras. Para tanto, pretende-se explorar os documentos oficiais que estão em uso no Brasil e trazer também documentos internacionais que estão - de certa forma e até certo grau - presentes nos estudos e na produção acadêmica do Brasil, e assim, constatar a presença ou não do plurilinguismo pedagógica e legislativamente no país.

Diante do exposto, vê-se a pertinência de se aprofundarem as discussões e o trabalho com o plurilinguismo entre os professores de línguas estrangeiras e estudantes no espaço escolar, para que, através do trabalho em sala de aula, esta perspectiva plurilíngue possa permear a formação sociocultural das nossas crianças e adolescentes, bem como dos seus professores, e assim contribuir para a autonomia, interação e a consciência da existência e inserção na dimensão glocal ${ }^{1}$, na qual todos nós estamos inseridos.

Posto isto, e sendo a língua um dos mais ricos elementos culturais e emancipatórios - no sentido de ser talvez um dos principais meios de acesso socioculturais, que suscitam respeito ao próprio sujeito, aos outros povos e respectivas culturas, bem como aos diferentes jeitos de viver - torna-se essencial o avanço nas pesquisas e propostas na área da educação notadamente no ensino de línguas estrangeiras.

Para tanto, como objetivo geral, temos: investigar a perspectiva plurilíngue para o ensino fundamental II através dos documentos educacionais oficiais brasileiros. E como objetivos específicos, temos: i) Levantar o referencial teórico; ii) Verificar o plurilinguismo com recorte para o ensino fundamental II; iii) Explorar o plurilinguismo no cenário educacional brasileiro.

\section{Procedimentos metodológicos}

\footnotetext{
${ }^{1}$ Definido por Manuel Castells (2014), o neologismo resultante da fusão dos termos global e local referese à presença da dimensão local na produção de uma cultura global.
} 
Para a elaboração deste artigo, far-se-á uma pesquisa de levantamento bibliográfico dos documentos oficiais brasileiros para o ensino de línguas sobre o plurilinguismo voltado para a educação básica - mais especificamente o $3^{\circ}$ e $\circ 4^{\circ}$ ciclo do ensino fundamental II - no que se diz respeito ao ensino de línguas.

A base teórica que respalda este trabalho repousa em estudos de Marconi e Lakatos (1992), os quais afirmam que a pesquisa bibliográfica é o levantamento sobre o tema de toda a bibliografia já publicada, em forma de livros, revistas, publicações avulsas e imprensa escrita. Sobre a abordagem, trabalhar-se-á a abordagem qualitativa, Godoy (1995, p. 58) afirma que:

[...] é a obtenção de dados descritivos sobre pessoas, lugares e processos interativos pelo contato direto do pesquisador com a situação estudada, para compreender os fenômenos segundo a perspectiva dos sujeitos, ou seja, dos participantes da situação em estudo.

Gil (1999, p. 94) corrobora, dizendo que "[...] métodos de pesquisa qualitativa estão voltados para auxiliar os pesquisadores a compreenderem pessoas e seus contextos sociais, culturais e institucionais". Utilizaremos, neste trabalho, o levantamento bibliográfico com abordagem qualitativa, uma vez que estabeleceremos como se dá o plurilinguismo na educação brasileira examinando os documentos oficiais e o atual contexto da pesquisa neste campo, e assim buscaremos compreender o tema e discorrer sobre o mesmo segundo este ponto de vista.

A pretensão é realizar um estudo descritivo exploratório. Segundo Marconi e Lakatos (2000, p. 77), os estudos descritivos têm como objetivo conhecer a natureza do fenômeno estudado, a forma como ele se constitui, as características e processos que dele fazem parte. Isto significa dizer que nas pesquisas descritivas, o pesquisador procura conhecer e interpretar a realidade, sem nela interferir para poder modificá-la.

Em se tratando da pesquisa exploratória, Gil (1999, p. 43) explica que a pesquisa exploratória tem como finalidade proporcionar maiores informações sobre o assunto que se vai investigar; facilitar a delimitação do tema da pesquisa; orientar a fixação dos objetivos e a formulação das hipóteses ou descobrir um novo tipo de enfoque para o assunto. Seu objetivo principal é o aprimoramento das ideias ou a descoberta de intuições. Neste trabalho, procuraremos dar um novo enfoque ao 
assunto através da busca pela visão do todo, ou seja, o levantamento do tema em fontes oficiais.

\section{Plurilinguismo: o que é?}

Antes de se definir o que é plurilinguismo, devemos ter em mente o que Souza (2019), ao estudar o plurilinguismo em sua tese e trabalhá-lo em sala de aula, lembranos pertinentemente, ele diz ser impossível caracterizar o aluno de hoje como monolíngue ou monocultural dada à popularização da internet nos anos 2000. Isto significa dizer que a escola já se encontra atrasada quanto à inserção do plurilinguismo na sala de aula. Há que se tornar uma realidade o plurilinguismo dentro da sala de aula, pois já faz parte da vida dos alunos de um modo amplo.

Segundo Souza (2019, p. 31), o plurilinguismo é:

[...] caracterizado pela capacidade de compreensão promovida por um indivíduo quando a sua experiência pessoal expande-se no seu contexto cultural, da sua LM, passando pela língua da sociedade geral até as línguas de outros povos que podem ser aprendidas na escola, por exemplo.

O plurilinguismo, no pensamento de Fontão $^{2}$, admite uma dimensão intercultural que, na prática, se traduz pela interação e/ou mediação sócio comunicativa. Desse modo, a educação em matéria de línguas constitui-se, sobretudo, como um espaço privilegiado de objetivos políticos consignados para a cidadania democrática (FONTÃO, 2011, p. 5).

Menezes ${ }^{3}$ completa demonstrando que:

Essa definição de plurilinguismo acentua o fato de que a experiência pessoal de um indivíduo, no seu contexto cultural, se expande para a sociedade em geral e, depois, para as línguas de outros povos (aprendidas na escola, na universidade) ou por experiência direta. Essas línguas e culturas não ficam armazenadas em compartimentos mentais rigorosamente separados. (MENEZES, 2013, p. 4)

\footnotetext{
2 FONTÃO, M. F. Multiculturalismo e Plurilinguismo. In: Quiosque das letras, 2011, disponível em: <www.quiosquedasletras.blogspot.com/...multiculturalismoeplurilin-guismo>. Acesso em: 07 abr. 2012. ${ }^{3}$ MENEZES, L. J. Plurilinguismo, Multilinguismo e Bilinguismo: Reflexões sobre a Realidade Linguística Moçambicana. Revista PERcursos Linguísticos, v. 3, n. 7, 2013, p.4.
} 
E resgatando o pensamento de Fontão, remarca-se que:

Ao contrário, constrói-se uma competência comunicativa, para a qual contribuem todo o conhecimento e toda a experiência das línguas, bem como a compreensão de como as línguas em questão se interrelacionam e interagem (FONTÃO, 2011, p. 5 apud MENEZES, 2013, p. 4).

Fica evidente que o plurilinguismo vai além de saber sua própria língua e variadas outras línguas. $O$ plurilinguismo abrange a experiência e a interação sociocultural dos indivíduos entre si, por isso que se torna revestido de significado para o contexto da educação básica, mais especificamente, do ensino fundamental II, já que os estudantes desta faixa etária (11 a 14 anos) já interagem com outros idiomas - seja na internet ou no seu contexto social - sendo também uma fase que o indivíduo participa de eventos de efervescente construção e reconstrução ininterrupta da sua própria linguagem - como exemplo, temos gírias e expressões próprias dessa fase que, muitas vezes, são oriundas de outros idiomas - e, portanto, seu próprio repertório linguístico. Logo, fica evidente a importância de se estudar os documentos oficiais brasileiros.

\subsection{O plurilinguismo e os documentos oficiais}

A fundamentação teórica para este artigo se debruça em documentos educacionais oficiais nacionais e internacionais com o intuito de levantar as diretrizes vigentes para o ensino de línguas na atualidade. Sendo assim, partimos da unidade de ensino em aulas de línguas, sendo, portanto, o texto a unidade de ensino referida.

Se o objetivo é que o aluno aprenda a produzir e a interpretar textos, não é possível tomar como unidade básica de ensino nem a letra, nem a sílaba, nem a palavra, nem a frase que, descontextualizadas, pouco têm a ver com a competência discursiva, que é questão central. Dentro desse marco, a unidade básica de ensino só pode ser o texto, mas isso não significa que não se enfoquem palavras ou frases nas situações didáticas específicas que o exijam. (PCN - LP, p. 29)

Dadas as características do plurilinguismo, vemos que uma prática pedagógica plurilíngue certamente aportará uma competência discursiva e, consequentemente, 
comunicativa, o que corrobora com o trecho acima destacado. Há que se ressaltar que, tendo o texto como unidade de ensino aliado a uma prática plurilíngue em sala de aula, tem-se, por conseguinte, a formação contínua de um sujeito autônomo e competente.

Os Parâmetros Curriculares Nacionais (PCN) trazem a noção de pluralismo linguístico entendido como a aceitação da existência de línguas diferentes e a promoção do ensino de várias línguas ( $P C N$ - L E, p. 22). O documento continua apontando a existência de critérios para se incluir uma língua estrangeira no currículo, a saber, fatores históricos, fatores relativos às comunidades locais e fatores relativos à tradição. Entretanto, o documento aponta tais critérios por reconhecer e denunciar a dificuldade que existe no Brasil em se oferecer outros idiomas. A este respeito se registra:

Independentemente de se reconhecer a importância do aprendizado de várias línguas, em vez de uma única, e de se pôr em prática uma política de pluralismo linguístico, nem sempre há a possibilidade de se incluir mais do que uma língua estrangeira no currículo. Os motivos podem ir da falta de professores até a dificuldade de incluir um número elevado de disciplinas na grade escolar. Assim, uma questão que precisa ser enfrentada é qual, ou quais línguas estrangeiras incluir no currículo. (PCN - L E, 1998, p. 22)

E ressalta ainda que:

Embora seu conhecimento seja altamente prestigiado na sociedade, as línguas estrangeiras, como disciplinas, se encontram deslocadas da escola. A proliferação de cursos particulares é evidência clara para tal afirmação. Seu ensino, como o de outras disciplinas, é função da escola, e é lá que deve ocorrer. (PCN - L E, 1998, p. 19)

É sabido que o entrave exposto nas páginas dos Parâmetros Curriculares Nacionais ainda vigora, em sua grande maioria, na realidade das escolas públicas brasileiras. Não há espaço na grade de horários, nem no currículo. Não há fartura de professores especializados em diversas línguas estrangeiras e, em alguns casos, não há também a valorização por parte da comunidade escolar do ensino de Língua Estrangeira. Contudo, o documento deixa claro que o ensino de línguas ocupa grande 
importância na formação do estudante e que é na escola que este ensino deve acontecer.

Um aspecto que chama atenção ao ler o documento é que o mesmo assinala a importância da língua estrangeira no que diz respeito à potencialização do engajamento discursivo. E remarca ainda que as línguas estrangeiras são um fator fundamental para o desenvolvimento deste engajamento discursivo no dia a dia da sala de aula, haja vista os objetivos presentes nos PCN's de Língua Estrangeira, os quais apontam mais uma vez para a importância do aspecto plurilíngue na formação do aluno, como fica nítido em seus objetivos:

- Identificar no universo que o cerca as línguas estrangeiras que cooperam nos sistemas de comunicação, percebendo-se como parte integrante de um mundo plurilíngue e compreendendo o papel hegemônico que algumas línguas desempenham em determinado momento histórico;

- Reconhecer que o aprendizado de uma ou mais línguas the possibilita o acesso a bens culturais da humanidade construídos em outras partes do mundo;

- Construir conhecimento sistêmico, sobre a organização textual e sobre como e quando utilizar a linguagem nas situações de comunicação, tendo como base os conhecimentos da língua materna;

- Construir consciência linguística e consciência crítica dos usos que se fazem da língua estrangeira que está aprendendo;

- Ler e valorizar a leitura como fonte de informação e prazer, utilizandoa como meio de acesso ao mundo do trabalho e dos estudos avançados;

- Utilizar outras habilidades comunicativas de modo a poder atuar em situações diversas. (PCN - LE, 1998, p.67)

Ao examinar tais objetivos e perceber o que se espera dos alunos do ensino fundamental ao longo dos quatro anos que estarão neste segmento, vê-se que o plurilinguismo está intrínseco em sua integridade, além de potencializar todos estes objetivos, já que estes mesmos objetivos apontam para o desenvolvimento de um sujeito que compreende o outro, ou seja, sua alteridade. Pertinentemente, sobre a alteridade, Fleuri (2003, p. 497 apud MOLAR, 2008) aponta:

Trata-se do desafio de se respeitar as diferenças e de integrá-las em uma unidade que não as anule, mas que ative o potencial criativo e 
vital da conexão entre diferentes agentes e entre seus respectivos contextos.

Isto significa dizer que é pela aprendizagem de línguas estrangeiras que o sujeito aprende mais sobre si mesmo e sobre um mundo plural, marcado por valores culturais diferentes e maneiras diversas de organização política e social (PCN - L E, p. 19). Aprende mais também sobre o funcionamento das línguas estrangeiras e da sua própria língua, possibilitando ao sujeito sua emancipação leitora, todos aspectos tão essenciais no contexto social contemporâneo - no qual se faz necessária uma população consciente e crítica, uma população que compreende seu entorno e, ao mesmo tempo, compreende o outro, outros povos, bem como o mundo globalizado e suas complexas conexões.

Ainda sobre o PCN, nota-se que, ao pensar no ensino fundamental II e na aprendizagem das línguas estrangeiras, em seus objetivos, o documento já abrange aspectos metacognitivos e intuitivos, quando ressalta a consciência linguística e crítica, e ainda, ao pontuar como e quando utilizar a linguagem em diferentes contextos. Outrossim, o documento abaliza tacitamente para o uso da linguagem em diferentes contextos ao trazer nos objetivos as habilidades comunicativas para atuar em situações diversas. Tais competências são hoje objeto de estudo de diversos trabalhos, os quais buscam resgatar os conhecimentos prévios e conhecimentos de mundo dos estudantes convergindo, deste modo, para a base do plurilinguismo.

Ainda sob a tutela da perspectiva do plurilinguismo na sala de aula de línguas, temos no Quadro Europeu Comum de Referência para Línguas, a seguinte distinção:

Assim, distingue-se "plurilinguismo" de "multilinguismo", que é entendido como o conhecimento de um certo número de línguas ou a coexistência de diferentes línguas numa dada sociedade. Pode chegar-se ao multilinguismo simplesmente diversificando a oferta de línguas numa escola ou num sistema de ensino específicos, incentivando os alunos a aprender mais do que uma língua estrangeira, ou, ainda, diminuindo a posição dominante do inglês na comunicação internacional. A abordagem plurilinguística ultrapassa esta perspectiva e acentua o facto de que, à medida que a experiência pessoal de um indivíduo no seu contexto cultural se expande, da língua falada em casa para a da sociedade em geral e, depois, para as línguas de outros povos (aprendidas na escola, na universidade ou por experiência directa), essas línguas e culturas não ficam armazenadas em compartimentos mentais rigorosamente separados; pelo contrário, constrói-se uma competência comunicativa, para a qual contribuem todo o conhecimento e toda a experiência das línguas e na qual as línguas se inter-relacionam e interagem. (QECRL, 2001, p. 23) 
A esta altura, é pertinente esclarecer um pouco mais o plurilinguismo, cuja definição no trecho acima foi didaticamente diferenciada do multilinguismo por tratarse de uma aprofundada capacidade de compreender diferentes idiomas a partir de experiências culturais (SOUZA, 2019, p. 31).

Não obstante, de acordo com o Quadro Europeu Comum de Referência para Línguas, no ensino de línguas, é preciso estabelecer laços educativos e de intercâmbio, além de desenvolver mais as capacidades de reconhecimento do que as capacidades de memória (QECRL, 2001, p. 20). Quando o QECRL cita laços de intercâmbio, logicamente vêm à tona os países vizinhos do Brasil, cujos habitantes são falantes do espanhol e do francês. Sem embargo, o inglês permanece na proposta, tendo em vista seu caráter glocal, porquanto o mesmo está presente em parte expressiva das diferentes linguagens com as quais os brasileiros têm contato de um modo geral. Diante desta diversidade e proximidade, é imprescindível o ensino plurilíngue nas escolas brasileiras, com vistas à possibilidade de uma ampliada competência linguística, bem como uma oportunidade de um expressivo caminho para a coexistência pacífica entre os povos de hoje e de amanhã.

O documento europeu de 2001 ainda aponta que:

\begin{abstract}
Deste ponto de vista, a finalidade do estudo das línguas modificou-se profundamente. Não se trata já de alcançar 'mestria' em uma, duas ou mesmo em três línguas (cada uma colocada no seu lugar), tendo como modelo final o "falante nativo ideal". Em vez disso, a finalidade passa a ser o desenvolvimento de um repertório linguístico no qual têm lugar todas as capacidades linguísticas. Isto implica, evidentemente, que a oferta das línguas em instituições de ensino deva ser diversificada e que os estudantes possam ter oportunidade de desenvolver uma competência plurilíngue. (QECRL, 2001, p. 24)
\end{abstract}

Ressalta-se também no QECRL que a aprendizagem de uma língua é tarefa de uma vida e que o ideal é que pudessem ser produzidos instrumentos utilizáveis por todos os profissionais do ensino das línguas na promoção do plurilinguismo (QECRL, 2001, p. 24). Não somente de uma vida inteira, mas, sobretudo, para a vida.

Sendo assim, é importante dizer que não pensamos diferente da perspectiva do QECRL. O principal objetivo do plurilinguismo é possibilitar ao aluno interagir verdadeiramente de modo mais competente e autônomo nos diferentes meios e em 
diferentes línguas através dos conhecimentos prévios que tendem a ser ampliados a partir do constante contato com os diversos idiomas consoante à ideia do plurilinguismo explanado anteriormente, principalmente se oportunizado o seu desenvolvimento paulatino em sala de aula, tanto é que o documento do Conselho da Europa complementa:

A competência plurilíngue e pluricultural refere-se à habilidade de usar línguas para propósitos de comunicação e tomar parte em interação intercultural, onde uma pessoa vista como um agente social tem proficiência, de níveis variados, em diversas línguas e experiência de diversas culturas (CONSELHO da EUROPA, 2001, p. 168).

A Base Nacional Comum Curricular (BNCC), por sua vez, ressalta que os estudantes devem interagir criticamente com a complexidade do mundo, favorecendo assim o respeito às diferenças e o diálogo intercultural, pluriétnico e plurilíngue (2017, p. 193). Diante desta perspectiva e sendo este um dos últimos documentos redigidos pelo Ministério da Educação do Brasil, percebemos que o plurilinguismo permeia todo o campo do ensino das línguas. Não poderia, logicamente, ser diferente, dada sua relevância para a formação estudantil do indivíduo nesta fase que compreende a educação básica brasileira. Fica claro, portanto, que o plurilinguismo inserido na sala de aula se incorporará à vida, haja vista seus benefícios para o sujeito aprendente. $A$ este respeito, o QECRL (2001, p. 31) distingue as principais competências que o estudante seguramente utilizará para vida, a saber:

As competências gerais dos utilizadores ou aprendentes de línguas incluem o conhecimento declarativo (saber), a competência de realização (saber-fazer), a competência existencial (saber-ser e saberestar) e a competência de aprendizagem (saber-aprender).

Este destaque que é dado aos saberes reveste-se de importância ao se estudar este tema do plurilinguismo, uma vez que se unem estes saberes aos quatro saberes ou quatro pilares da educação da UNESCO ${ }^{4}$, cujo estudo e indicação devem estar presentes em todos os planos de aula de cada professor, seja qual for sua área.

\footnotetext{
${ }^{4}$ Os 4 pilares da educação, de acordo com a UNESCO, são: aprender a conhecer, aprender a fazer, aprender a viver juntos e aprender a ser.
} 


\subsection{A Lei de Diretrizes e Bases}

Seguindo o panorama dos documentos oficiais brasileiros que fornecem diretrizes a serem seguidas no ensino de línguas para a educação básica e, em especial, para o fundamental II, trazemos a lei de diretrizes e bases de $n^{\circ} 9.394$.

No seu artigo 26, parágrafo 5 , a referida lei diz que a partir do sexto ano será ofertada a língua inglesa. Diferentemente, a versão anterior dava a oportunidade de cada unidade escolar brasileira selecionar suas línguas estrangeiras modernas, de acordo com as necessidades e escolhas da comunidade escolar. Porém, publicada a nova versão em 2017, o que se percebe é uma total contradição frente aos outros documentos já apresentados neste texto que regem e orientam igualmente a educação, bem como o ensino de línguas no Brasil e no mundo.

Como pontuado acima, os documentos estudados neste artigo anteriormente remontam à redação anterior da LDB, cuja escolha ficaria a cargo da comunidade escolar. Através da MP 476, o governo brasileiro desconsidera o contexto de cada comunidade e desconsidera ainda a perspectiva plurilíngue e glocal que está presente em todos os documentos oficiais para o ensino de línguas. A LDB passa então a limitar a possibilidade de o estudante ter amplo e variado acesso a bens culturais e linguísticos ao passo que restringe sua aprendizagem a somente dois idiomas: português e inglês, perpetuando a ideia de hegemonia da língua inglesa frente a outros idiomas. Mesmo sendo também da área de inglês, acredito que há um empobrecimento, uma perda mesmo para o aluno, pois se restringe o acesso a bens culturais e a conhecimentos que trazem cada língua. Neste sentido, refletindo sobre $o$ papel da escola, destaca-se no QECRL, 2001, p.24, que

...uma vez admitido o facto de que a aprendizagem de uma língua é tarefa de uma vida, torna-se fulcral o desenvolvimento da motivação, da capacidade e da confiança do jovem para poder enfrentar novas experiências linguísticas.

E retornando ao envolvimento do plurilinguismo e da comunidade, vem daí também o prejuízo. Sendo o Brasil um país pluricultural, para muitas comunidades locais, sua identidade e história são diariamente lançadas fora do ambiente escolar, 
ao ceifar da sala de aula o repertório linguístico e cultural que vai se acumulando nas famílias e nos espaços da escola ao longo dos anos, riqueza esta tão difícil de se recuperar. Como exemplo deste cenário, temos as escolas que, de acordo com a anuência da comunidade, acolhem, devido ao seu contexto, as colônias de italianos, alemães, dentre outros. São bem conhecidos os contextos de muitos brasileiros, os quais possuem antepassados de outras nacionalidades e que por isso pretendem manter suas tradições. $E$ ainda temos a comunidade profissional, os professores que perdem muito também ao se esgotarem ou rarearem seus campos de trabalho. Como exemplos, podemos citar os licenciados em espanhol, francês, alemão ou italiano que, uma vez sendo egressos da universidade pública, ao buscarem colocação profissional na própria rede pública de ensino brasileira, já possuíam pouco campo de trabalho e, agora, com a nova redação da LDB, podem perder ainda mais tal perspectiva e inserção profissional.

Sendo assim, diante de todo levantamento que foi realizado neste artigo até aqui, considero, portanto, um retrocesso acompanhado de uma infeliz contradição, sendo o atual registro da LDB um arranjo engessado e, consequentemente, parado no tempo, uma vez que os estudos neste campo - o plurilinguismo - avançam a passos largos no Brasil e no mundo e revelam que, para um caminho de diálogo entre os povos, é urgente uma realidade de escolas plurilíngues.

\section{Conclusão}

Quem não conhece línguas estrangeiras, não sabe nada da própria.

Johann Goethe

Este artigo buscou, no cenário educacional brasileiro, o lugar do plurilinguismo e, deste modo, evidenciou sua consolidada presença e importância na atualidade para a formação do aluno, do professor, como também para sua prática em sala de aula e campo de atuação. Nesta linha, projetamos ao leitor um panorama do tema, estudando os documentos que hoje direcionam as ações no campo educacional do ensino de línguas, cujo objetivo foi explicitar para o leitor a contemporaneidade do plurilinguismo, bem como sua pertinência nos diferentes contextos e regiões do país e alhures. 
Para tanto, como base para o estudo aprofundado deste tema, utilizamos os Parâmetros Curriculares Nacionais (PCN), a Base Nacional Comum Curricular (BNCC), o Quadro Europeu Comum de Referência para Línguas (QECRL) do Conselho da Europa, e, finalmente, a Lei de Diretrizes e Bases da Educação (LDB) para estabelecer o cenário que envolve o tema principal deste artigo, o plurilinguismo, e para expor nosso ponto de vista sobre a atual proposta de ensino de línguas para o segmento da educação básica brasileira, mais especificamente, pensando no ensino fundamental II, ou seja, estudantes de 11 a 14 anos majoritariamente.

Acreditamos que este artigo se coloca como uma contribuição e como o início de uma constante pesquisa sobre esta temática, basta ver o alto grau de interesse e caráter inovador que o mesmo nos despertou. Esperamos que o mesmo aconteça aos colegas professores de línguas que terão contato com esta leitura e que os mesmos ampliem, deste modo, sua leitura de mundo para se permitir também mergulhar neste tema, estudá-lo e produzir materiais como consequência desta nova prática e formação continuada, já que, parafraseando Goethe, conhecer novos idiomas reveste de sentido a nossa língua e nos faz perceber a riqueza da alteridade.

\section{Referências}

BRASIL. Lei de Diretrizes e Bases da Educação. Brasília 1996.

BRASIL. Base Nacional Comum Curricular (BNCC). Educação é a Base. Brasília, MEC/CONSED/UNDIME, 2017.

CONSELHO DA EUROPA. Quadro europeu comum de referência para as línguas aprendizagem, ensino, avaliação. Porto: Asa Editores, 2001.

FLEURI, R. M. Intercultura e Educação. Revista Brasileira de Educação. Santa Catarina, n. 23, maio/jun./jul./ago, 2003. In: MOLAR, J. O. A Alteridade na Educação: Noção em Construção Revista NUPEM, Campo Mourão, v.3, n.5, ago./dez. 2011.

FONTÃO, M. F. Multiculturalismo e Plurilinguismo. In Quiosque das letras, 2011, disponível em: <www.quiosquedasletras.blogspot.com/...multiculturalismoeplurilinguismo>. Acesso em 01 ago. 2020.

GIL, A. C. Métodos e técnicas de pesquisa social. São Paulo: Atlas, 1999.

GODOY, Arilda Schmidt. Introdução à pesquisa qualitativa e suas possibilidades. RAE - Revista de Administração de Empresas, São Paulo, v. 35, n. 2, 1995. 
MARCONI, M. de A.; LAKATOS, Eva Maria. Metodologia do trabalho científico. São Paulo: Editora Atlas, 1992. 4a ed. p. 43 e 44.

MENEZES, L. J. .J. M. Plurilinguismo, Multilinguismo e Bilinguismo: Reflexões sobre a Realidade Linguística Moçambicana. Revista PERcursos Linguísticos. V. 3 n. 7, 2013.

MINISTÉRIO DA EDUCAÇÃO E DO DESPORTO. Parâmetros curriculares Nacionais. Brasília: MEC/SEF, 1997.

SOUZA, R. E. G. Efeitos do plurilinguismo e intercompreensão na aprendizagem de língua portuguesa na Educação Básica. Revista Letras Raras, 2017. 